\title{
Case Report \\ Yogi Detox Tea: A Potential Cause of Acute Liver Failure
}

\author{
Keerthana Kesavarapu, ${ }^{1}$ Mitchell Kang, ${ }^{1}$ Jaewook James Shin, ${ }^{2}$ and Kenneth Rothstein ${ }^{3,4}$ \\ ${ }^{1}$ Department of Internal Medicine, Drexel University Hospital, Philadelphia, PA, USA \\ ${ }^{2}$ Drexel School of Medicine, Philadelphia, PA, USA \\ ${ }^{3}$ Department of Gastroenterology, Drexel University Hospital, Philadelphia, PA, USA \\ ${ }^{4}$ Department of Hepatology, Drexel University Hospital, Philadelphia, PA, USA
}

Correspondence should be addressed to Keerthana Kesavarapu; kkesavarapu@gmail.com

Received 15 April 2017; Revised 4 August 2017; Accepted 13 August 2017; Published 24 October 2017

Academic Editor: Hideto Kawaratani

Copyright (C) 2017 Keerthana Kesavarapu et al. This is an open access article distributed under the Creative Commons Attribution License, which permits unrestricted use, distribution, and reproduction in any medium, provided the original work is properly cited.

\begin{abstract}
We present a case of acute fulminant liver failure from a liver detoxification tea. We present a 60 -year-old female with weakness, lethargy, scleral icterus, jaundice, and worsening mental status. She drank herbal tea three times a day for 14 days prior to symptom development. Liver tests were elevated. Remaining laboratory tests and imaging were negative for other etiologies. An ultrasoundguided liver biopsy showed submassive necrosis. A literature search on the ingredients shows six ingredients as having hepatotoxic effects and remaining ingredients as having very sparse hepatoprotective data. Healthcare professionals should discuss herbal medication and tea use and report adverse effects.
\end{abstract}

\section{Introduction}

The American Association for the Study of Liver Diseases (AASLD) defines acute fulminant liver failure as an acute deterioration of function resulting in altered mentation and coagulopathy without any known preexisting disease [1]. In 308 patients from 17 tertiary care centers participating in US Acute Liver Failure Study Group, drug reactions including acetaminophen overdose were the presumptive cause in $52 \%$ of cases [2]. Prevalent medication offenders include acetaminophen, mushrooms, and antiepileptics (phenytoin and valproic acid); however herbal supplement induced hepatotoxicity is gaining prevalence. According to the Drug-Induced Liver Injury Network (DILIN), causes of acute liver failure (ALF) from herbal supplements have increased from $7 \%$ to $20 \%$ over their study period from 2007 to 2013 [3]. This number is probably a gross underestimation as patients do not report use to their physicians and physicians do not report side effects to the Food and Drug Association (FDA) and might not be identified by DILIN. Here we report a case of ALF after the use of an herbal detoxification tea marketed to be hepatoprotective.

\section{Case Report}

A 60-year-old female with past medical history of hypertension presented with new-onset generalized weakness and lethargy worsening over the past two weeks. She denied any fevers, chills, changes in stool, changes in mental status, sick contacts, or recent travel. Her past medical history was significantly only for obesity. Her social history included no tobacco use, frequent alcohol consumption (3 glasses of wine every night), no IV drug use, no acetaminophen use, and no high risk sexual activity. Her alcohol use has been stable since she started drinking ten years ago. Previous laboratory testing showed normal liver function. She was fully vaccinated with no history of hepatitis. Her only home medication was hydrochlorothiazide, which she had been taking for years. She had no preexisting liver disease with normal liver function tests prior to this admission. She reported drinking Yogi Detox herbal tea three times a day for 14 days prior to symptom development. As per the patient, she was consuming this tea as a cleanse.

Physical examination demonstrated a normotensive and afebrile patient in mild distress. the patient was jaundiced 
TABLE 1: Hepatic function panel on day of admission, 1 week and 2 weeks later.

\begin{tabular}{lccc}
\hline Laboratory testing & On admission & 1 week & 2 weeks \\
\hline $\begin{array}{l}\text { Aspartate aminotransferase } \\
\text { (5-35 U/L) }\end{array}$ & 450 & 1864 & 51 \\
$\begin{array}{l}\text { Alanine aminotransferase } \\
(4-35 \text { U/L) }\end{array}$ & 583 & 2162 & 82 \\
$\begin{array}{l}\text { Alkaline phosphatase } \\
(30-99 \text { U/L) }\end{array}$ & 202 & 143 & 72 \\
$\begin{array}{l}\text { Total bilirubin } \\
(0.2-1.2 \text { mg/dl) }\end{array}$ & 27 & 43 & 30 \\
$\begin{array}{l}\text { Direct bilirubin } \\
(0.01-0.19 \mathrm{mg} / \mathrm{dl})\end{array}$ & 20 & 33 & 21 \\
INR $(0.9-1.2)$ & 4 & 2.7 & 7.8 \\
\hline
\end{tabular}

TABLE 2: Roussel Uclaf Causality Assessment Method, an assessment of the causality of drug-induced liver injury.

\begin{tabular}{ll}
\hline Items for mixed liver injury & Score in our patient \\
\hline $\begin{array}{l}\text { Time to onset from cessation of drug/herb: } \\
<15 \text { days }\end{array}$ & +2 \\
$\begin{array}{l}\text { Course of ALT after cessation of drug/herb: } \\
\text { decrease } \geq 50 \% \text { within } 180 \text { days }\end{array}$ & +2 \\
$\begin{array}{l}\text { Risk factors: alcohol use ( }>2 \text { drinks/d for } \\
\text { women) and Age } \geq 55\end{array}$ & +1 \\
Concomitant drug/herbs: none & 0 \\
$\begin{array}{l}\text { Alternative causes: all causes ruled out } \\
\text { Previous hepatotoxicity of the drug/herb: }\end{array}$ & +2 \\
reaction published but unlabeled & +1 \\
Response to unintentional reexposure: none & 0 \\
Total score & 8 \\
\hline
\end{tabular}

with scleral icterus. Examination demonstrated a soft and nondistended abdomen with moderate right upper quadrant tenderness. Mental status was intact on admission; however, on the ninth day of the admission she became lethargic and developed asterixis. Initial laboratory tests are depicted in Table 1. Radiological examinations performed consisted of an abdominal ultrasound with Doppler's and triplephase computerized tomography (CT) with contrast of the abdomen, which were normal. Extensive laboratory testing was ordered to determine the etiology of her liver failure. Serological markers including those for autoimmune hepatitis (Anti-KLM antibodies, ANA, and AMA), viral hepatitis (A, B, C, and D), Wilson's disease (ceruloplasmin), and alpha1-antitrypsin deficiency were analyzed and found to be negative. In addition, CMV, EBV, VZV, and HSV were negative. HEV testing was not performed as there is no approved test in the United States [4].

There was concern that the cause of her liver injury might have been due to her Yogi detox herbal tea consumption. Using the 2016 Roussel Uclaf Causality Assessment Method (RUCAM) score as highlighted in Table 2, the relationship between this herbal tea and liver injury was determined [26].

The $R$ ratio, which is the initial step in the RUCAM assessment, was 8.16 indicating a hepatocellular pattern of
TABle 3: 18-ingredient list contained in the Yogi Detox Tea and the articles published in PubMed highlighting their hepatotoxicity.

\begin{tabular}{lc}
\hline Ingredient & Number of hepatotoxic articles/case reports \\
\hline Sarsaparilla root & 0 \\
Cinnamon bark & $1[5]$ \\
Ginger root & 0 \\
Licorice root & 0 \\
Dandelion root & 0 \\
Cardamom seed & 0 \\
Clove bud & 0 \\
Black pepper & $1[6]$ \\
Juniper berry & $1[7]$ \\
Long pepper berry & 0 \\
Phellodendron bark & 0 \\
Rhubarb root & $4[8-11]$ \\
Skullcap root & $7[12-18]$ \\
Coptis root & 0 \\
Forsythia fruit & 0 \\
Gardenia fruit & $7[19-25]$ \\
Honeysuckle & 0 \\
Winter melon & 0 \\
\hline
\end{tabular}

injury. In our patient, her RUCAM score was 7 ( 2 points for time from drug intake $<15$ days, 2 points for $\geq 50 \%$ reduction of ALT after herb cessation, 1 point for risk factors of alcohol use, 2 points for other causes being ruled out, and 1 point for previous reaction to herb but unlabeled), which indicates that the detox tea is the probable offending agent of her hepatic injury. Given the worsening clinical picture, an ultrasound-guided liver biopsy was performed. The liver histology was notable for submassive necrosis with portal, periportal, and panlobular inflammation with lymphocytes, numerous neutrophils, plasma cells, and few eosinophils (Figures 1(a) and 1(b)). Hepatocyte ballooning, Mallory hyaline, and single cell apoptosis were also noted. Her lethargy progressed to somnolence requiring intubation. She was placed on the transplant list on day 15 and passed away on day 17.

\section{Discussion}

The prevalence of herbal supplementation intake has been increasing; however, their use is unregulated by the Food and Drug Administration and unsupervised by medical professionals [27]. The patient discussed in this case consumed Yogi Detoxification tea, an American produced tea that is an amalgamation of eighteen herbs marketed to be hepatoprotective. The Ingredients of this tea are listed in Table 3. Literature review of these ingredients in PubMed showed that all had articles endorsing hepatoprotection. The basis behind protection is hypothesized and demonstrated to be through their antioxidant and anti-inflammatory properties. However, literature search of these ingredients showed that less than $10 \%$ were done with human or liver-injury cell 


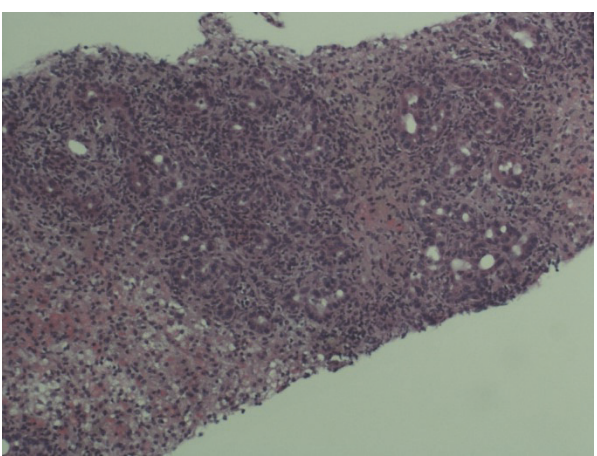

(a)

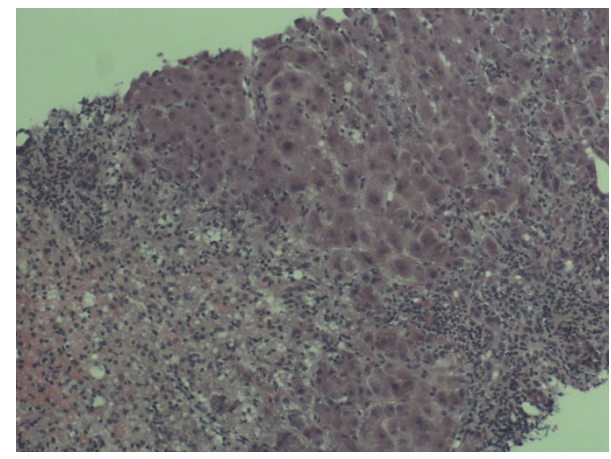

(b)

FIGURE 1: US-guided liver biopsy showing submassive necrosis.

models. Animal studies may not be able to mimic the complex process of herb-induced inflammatory response of human physiology and progress. Therefore, the safety and efficacy may not be translatable to human trials. Not only is more basic research needed to understand the pathophysiology of hepatotoxicity, but more human trials are necessary to elucidate potential effects.

Six ingredients had one or more published studies associating it with hepatotoxicity. Hepatic toxicity caused by Gardenia has been demonstrated to cause oxidative stress-induced hepatocyte necrosis and apoptosis in murine models. Seven different articles attributed Gardenia's component geniposide to its hepatotoxic effect [19-25]. Yang described liver biopsy findings in rats exposed to geniposides that showed swollen and necrotic cells and an inflammatory infiltrate similar to the biopsy of our patient [25]. Similarly, skullcap root, another ingredient, was shown in a two-year retrospective study of 1169 hospitalized patients to be a common cause of hepatotoxicity [12]. Four case reports featuring seven patients show complications can range from mild hepatitis to acute hepatic failure requiring transplantation [13-16]. Cinnamon bark, black pepper, juniper berry, and rhubarb root, other ingredients of this tea, have all been associated with liver dysfunction [5-7].

While evidence suggests that the patient's acute change is associated with tea consumption, the exact toxicity-inducing agent of this tea is unclear. Preexisting alcohol consumption in combination with the herbal supplementation may have hastened the progression of hepatotoxicity. In addition to the 19 ingredients, herbal products are contaminated with other toxins or added adulterants that are not advertised on the packaging. In addition, ingestion of multiple substances may increase the risk of hepatotoxicity. This "cluster" effect of herbal supplements has not been elucidated in the literature; however, it has been known that risk factors such as alcohol ingestion are susceptible to drug toxicity from alterations in drug metabolism. Regardless, herbal tea consumption must be monitored by healthcare professionals, and any side effects should be reported to specific organizations in order to take regulatory measures and control usage of such products.

\section{Consent}

Informed consent was obtained from the patient involved.

\section{Disclosure}

The author guarantor is Keerthana Kesavarapu. The remaining authors aided in caring for and editing the content of this case report. An earlier version of this work was presented as a poster at the Annual Scientific Meeting of the American College of Gastroenterology being held October 14-19, 2016.

\section{Conflicts of Interest}

The authors declare that there are no conflicts of interest regarding the publication of this paper.

\section{References}

[1] W. M. Lee, A. M. Larson, and R. T. Stravitz, "AASLD position paper: the management of acute liver failure," in Hepatology, vol. 55, pp. 965-967, 2012.

[2] G. Ostapowicz, R. J. Fontana, F. V. Schioødt et al., "Results of a prospective study of acute liver failure at 17 tertiary care centers in the United States," Annals of Internal Medicine, vol. 137, no. 12, pp. 947-954, 2002.

[3] V. J. Navarro, H. Barnhart, H. L. Bonkovsky et al., "Liver injury from herbals and dietary supplements in the U.S. drug-induced liver injury network," Hepatology, vol. 60, no. 4, pp. 1399-1408, 2014.

[4] Centers for Disease Control and Prevention, "Hepatitis E for Health Professionals," 2017, https://www.cdc.gov/hepatitis/ hev/hevfaq.htm.

[5] N. Iwata, M. Kainuma, D. Kobayashi et al., "The relation between hepatotoxicity and the total coumarin intake from traditional Japanese medicines containing cinnamon bark," Frontiers in Pharmacology, vol. 7, article no. 174, 2016.

[6] P. J. Rao, S. D. Kolla, F. Elshaari et al., "Effect of piperine on liver function of CF-1 albino mice," Infectious Disorders-Drug Targets, vol. 15, no. 2, pp. 131-134, 2015.

[7] Y. Liu, T. J. Flynn, M. S. Ferguson, E. M. Hoagland, and L. L. Yu, "Effects of dietary phenolics and botanical extracts on hepatotoxicity-related endpoints in human and rat hepatoma cells and statistical models for prediction of hepatotoxicity," Food and Chemical Toxicology, vol. 49, no. 8, pp. 1820-1827, 2011.

[8] L.-N. He, A.-H. Yang, T.-Y. Cui et al., "Reactive metabolite activation by CYP2C19-mediated rhein hepatotoxicity," Xenobiotica, vol. 45, no. 4, pp. 361-372, 2015. 
[9] J.-B. Wang, W.-J. Kong, H.-J. Wang et al., “Toxic effects caused by rhubarb (Rheum palmatum L.) are reversed on immature and aged rats," Journal of Ethnopharmacology, vol. 134, no. 2, pp. 216220, 2011.

[10] J. B. Wang, M. a. YG, P. Zhang, and C. Jin, "Effect of processing on the chemical contents and hepatic and renal toxicity of rhubarb studied by canonical correlation analysis," Yao Xue Xue Bai, vol. 44, no. 8, pp. 885-890, 2009.

[11] J. Wang, Y. Zhao, X. Xiao et al., "Assessment of the renal protection and hepatotoxicity of rhubarb extract in rats," Journal of Ethnopharmacology, vol. 124, no. 1, pp. 18-25, 2009.

[12] H. J. Woo, H. Y. Kim, E. S. Choi et al., "Drug-induced liver injury: a 2-year retrospective study of 1169 hospitalized patients in a single medical center," Phytomedicine, vol. 22, no. 13, pp. 1201-1205, 2015.

[13] R. Dhanasekaran, V. Owens, and W. Sanchez, "Chinese skullcap in move free arthritis supplement causes drug induced liver injury and pulmonary infiltrates," Case Reports in Hepatology, vol. 2013, Article ID 965092, 4 pages, 2013.

[14] L. Yang, A. Aronsohn, J. Hart, and D. Jensen, "Herbal hepatoxicity from Chinese skullcap: a case report," World Journal of Hepatology, vol. 4, no. 7, pp. 231-233, 2012.

[15] S. A. Linnebur, O. C. Rapacchietta, and M. Vejar, "Hepatotoxicity associated with Chinese skullcap contained in move free advanced dietary supplement: two case reports and review of the literature," Pharmacotherapy, vol. 30, no. 7, 2010.

[16] O. A. Jorge and A. D. Jorge, "Hepatotoxicity associated with the ingestion of Centella asiatica," Revista Española de Enfermedades Digestivas, vol. 97, no. 2, pp. 115-124, 2005.

[17] J.-Y. Wang, C.-Y. Lee, P.-J. Pan et al., "Herb-induced autoimmune-like hepatitis in C57BL/6J mice," Liver International, vol. 34, no. 4, pp. 583-593, 2014.

[18] C. Bunchorntavakul and K. R. Reddy, "Review article: herbal and dietary supplement hepatotoxicity," Alimentary Pharmacology \& Therapeutics, vol. 37, no. 1, pp. 3-17, 2013.

[19] K. Wang, R.-M. Jin, and C.-X. Chen, "Comparative study on hepatic toxicity of gardeniae fructus and Huanglian Diedu decoction," Zhongguo Zhongyao Zazhi, vol. 38, no. 14, pp. 23652368, 2013.

[20] J. Wei, F. Zhang, Y. Zhang et al., "Proteomic investigation of signatures for geniposide-induced hepatotoxicity," Journal of Proteome Research, vol. 13, no. 12, pp. 5724-5733, 2014.

[21] Y. Ding, T. Zhang, J.-S. Tao, L.-Y. Zhang, J.-R. Shi, and G. Ji, "Potential hepatotoxicity of geniposide, the major iridoid glycoside in dried ripe fruits of Gardenia jasminoides (Zhi-zi)," Natural Product Research (Formerly Natural Product Letters), vol. 27, no. 10, pp. 929-933, 2013.

[22] H. Zhang, W. Wu, F. Li, W. Song, Y. He, and M. Yang, "Study on liver protection, cholagogic effect and hepatotoxicity of Gardeniae fructus," Zhongguo Zhongyao Zazhi, vol. 36, no. 19, pp. 2610-2614, 2011.

[23] T. Nuanyai, R. Sappapan, T. Teerawatananond, N. Muangsin, and K. Pudhom, "Cytotoxic 3,4-seco-cycloartane triterpenes from Gardenia sootepensis," Journal of Natural Products, vol. 72, no. 6, pp. 1161-1164, 2009.

[24] Y. Tetsuo, T. Yuji, N. Tsutomu et al., "Hepatotoxicity of gardenia yellow color in rats," Toxicology Letters, vol. 44, no. 1-2, pp. 177$182,1988$.

[25] H. J. Yang, F. u. MH, W. u. ZL, and R. X. Liang, "Experimental studies on hepatotoxicity on rats induced by fructus Gardeniae," Zhongguo Zhong Yao Za Zhi, vol. 31, no. 13, pp. 1091-1093, 2006.
[26] G. Danan and R. Teschke, "RUCAM in drug and herb induced liver injury: the update," International Journal of Molecular Sciences, vol. 17, no. 1, 14 pages, 2016.

[27] C. Wu, C. Wang, M. Tsai, W. Huang, and J. Kennedy, “Trend and pattern of herb and supplement use in the United States: results from the 2002, 2007, and 2012 national health interview surveys," Evidence-Based Complementary and Alternative Medicine, vol. 2014, Article ID 872320, 7 pages, 2014. 


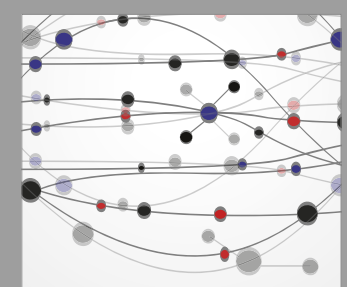

The Scientific World Journal
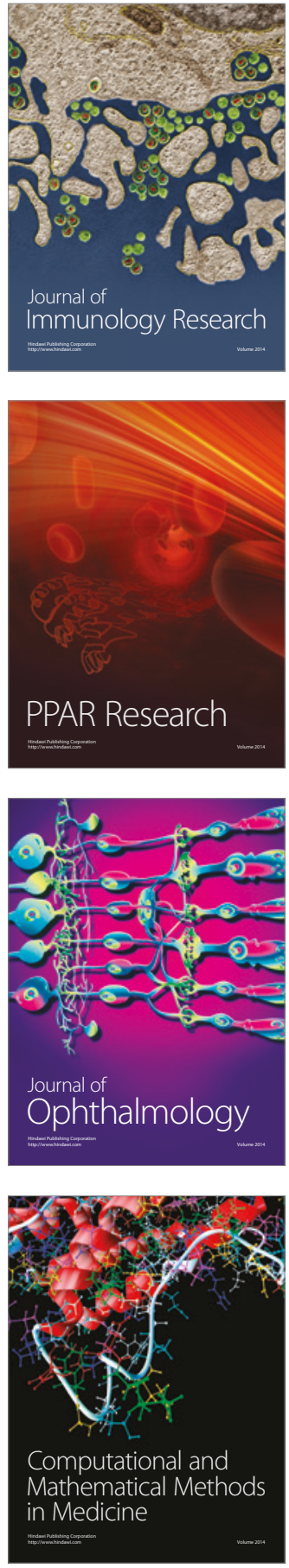

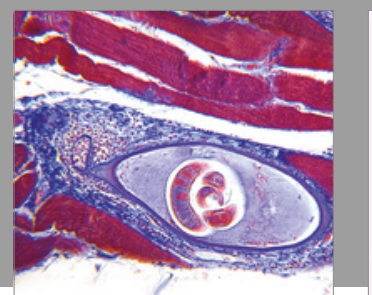

Gastroenterology Research and Practice
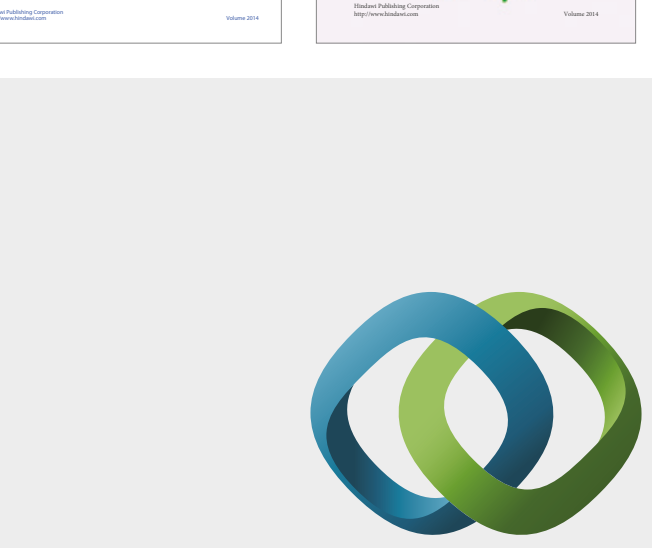

\section{Hindawi}

Submit your manuscripts at

https://www.hindawi.com
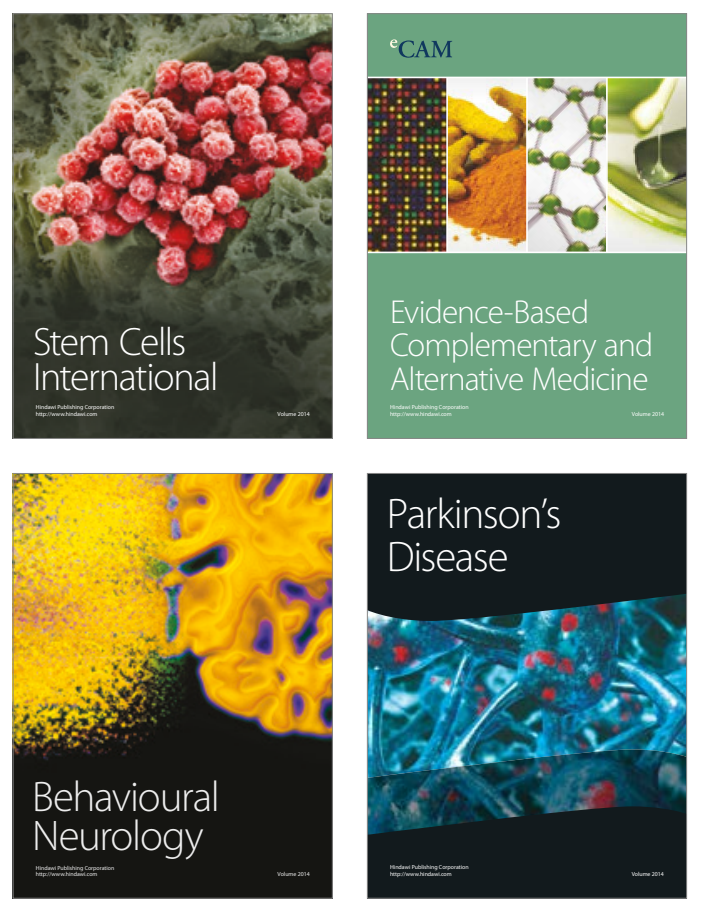
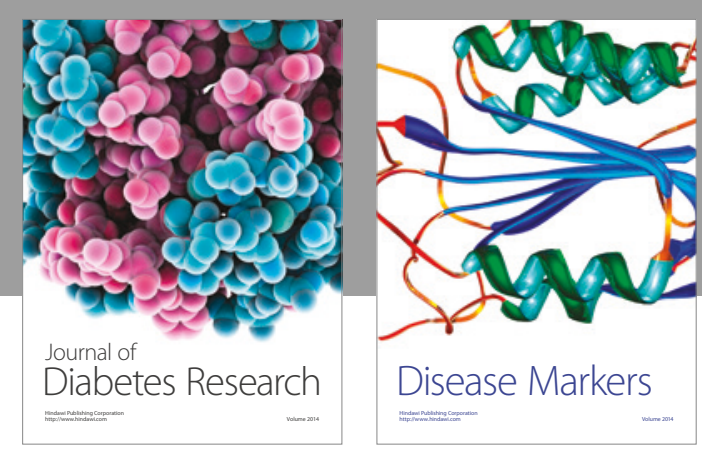

Disease Markers
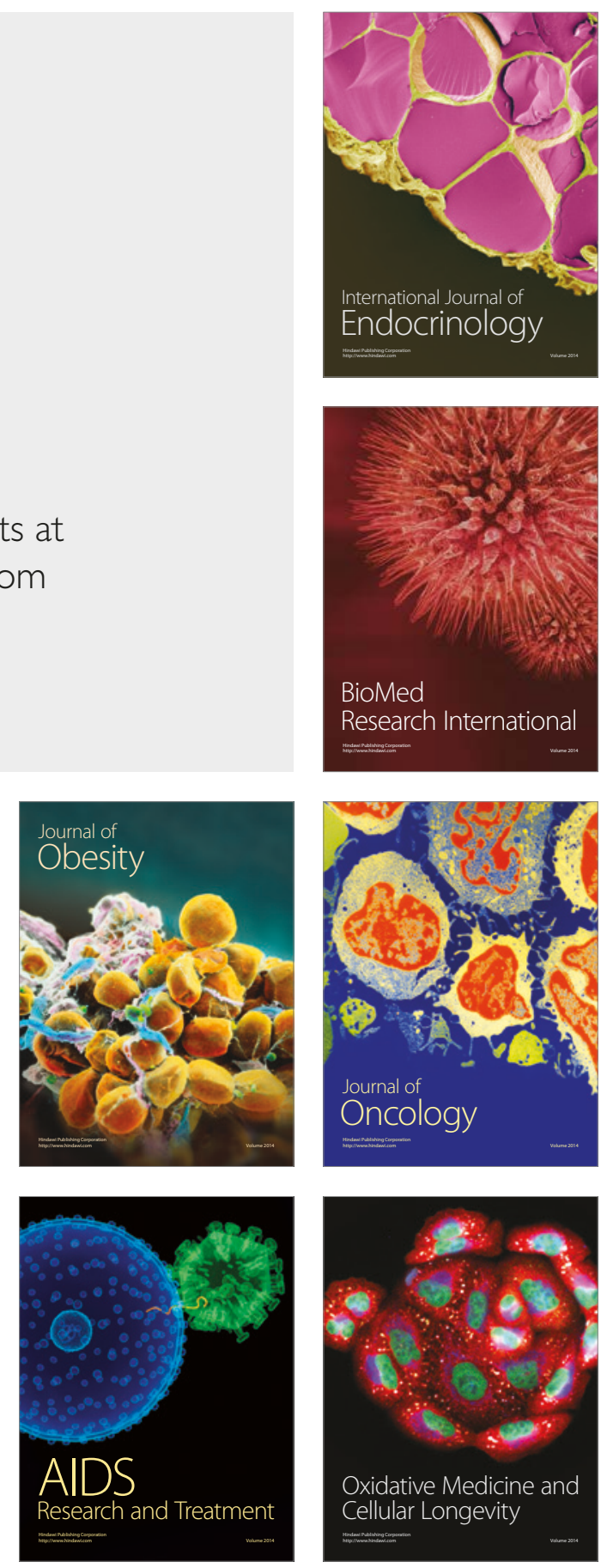